Supplementary Materials for:

\title{
Representing future generations in the deliberative valuation of ecosystem
} services

Georgia Mavrommati ${ }^{1 *}$, Shannon Rogers ${ }^{2}$, Richard B. Howarth ${ }^{3}$, Mark E. Borsuk ${ }^{4}$

${ }^{1 *}$ School for the Environment, University of Massachusetts Boston, Boston, Massachusetts, US

Email: Georgia.mavrommati@umb.edu, Corresponding Author

${ }^{2}$ University of New Hampshire, Durham, New Hampshire, US

${ }^{3}$ Environmental Studies Program, Dartmouth College, Hanover, New Hampshire, US

${ }^{4}$ Civil and Environmental Engineering, Duke University, Durham, North Carolina

\section{List of contents}

Text S1. Ecosystem services (attributes selection).

Text S2. Questionnaire survey S2.

Figure S1. Demographic characteristics of the questionnaire survey. Age and years living in the community

Figure S2. Demographic characteristics of the questionnaire survey. Sex, gender, political affiliation and educational level.

Table S1. Participants characteristics compared to New Hampshire population. 


\section{Text S1}

We used expert judgement of our team, comprised of natural and social scientists, to define attributes to characterize ecosystem services subject to two criteria: (i) importance and salience by the general public and; (ii) capacity to translate the attributes into environmental indicators that can be measured or modelled under current and future conditions (Samal et al. 2017). 


\section{A Survey to Understand Public Opinion on Environmental Quality in the Merrimack River Watershed, New Hampshire}

General Instructions: Please fill in the circle corresponding to your answer. Please select only one answer unless otherwise specified.

Q1. Please indicate the zip code where your home is located.

Q2. Please indicate which of the following dates you are available to participate in a one day workshop in Concord. You can choose more than one dates.

$6 / 8 / 15$

$6 / 9 / 15$

$6 / 10 / 15$

$6 / 11 / 15$

$6 / 12 / 15$

$6 / 15 / 15$

$6 / 16 / 15$

$6 / 17 / 15$

$6 / 18 / 15$

$6 / 19 / 15$

Q3. How long have you been living in your current community?

Years

Q4. How would you rate the overall environmental quality in your local community?

Very Good

Good

Fair

Poor

Very Poor 
Q5. Please indicate the importance you place on the following benefits derived from the environment?

b. Drinking Water Supply

c. Coastal Water Quality

d. Flood Protection

e. Local Agricultural Production

f. Outdoor Summer Recreation

g. Outdoor Winter Recreation

h. Fall Foliage ("Leaf-Peeping")

i. Forests for Climate Protection

j. Forest Wood Products

k. Forest Biodiversity

\begin{tabular}{|c|c|c|c|c|}
\hline Unimportant & $\begin{array}{c}\text { Slight } \\
\text { Importance }\end{array}$ & $\begin{array}{l}\text { Moderately } \\
\text { Important }\end{array}$ & Important & $\begin{array}{c}\text { Very } \\
\text { Important }\end{array}$ \\
\hline 0 & 0 & 0 & 0 & 0 \\
\hline$\bigcirc$ & 0 & $\bigcirc$ & $\bigcirc$ & $\bigcirc$ \\
\hline 0 & 0 & 0 & 0 & 0 \\
\hline 0 & 0 & 0 & 0 & 0 \\
\hline 0 & 0 & $\bigcirc$ & $\bigcirc$ & $\bigcirc$ \\
\hline$\bigcirc$ & 0 & $\bigcirc$ & 0 & 0 \\
\hline 0 & 0 & 0 & 0 & 0 \\
\hline$\bigcirc$ & 0 & 0 & 0 & 0 \\
\hline 0 & $\bigcirc$ & 0 & 0 & 0 \\
\hline 0 & 0 & 0 & 0 & 0 \\
\hline$\bigcirc$ & 0 & 0 & 0 & 0 \\
\hline
\end{tabular}

Q6. How strongly do you agree or disagree with the following statements?

a. I feel good about myself when I undertake actions that help the environment

\begin{tabular}{ccccc} 
& \multicolumn{3}{c}{ Neither } & \\
Strongly & Somewhat & Disagree & Somewhat & Strongly \\
Disagree & Disagree & nor Agree & Agree & Agree
\end{tabular}

b. As long as I follow laws and regulations, I don't need to do any more to reduce environmental harm to other people

c. I am not concerned about depletion of natural resources as long as I can find suitable substitutes for myself and my family

d. I am not concerned about conserving resources for future generations

e. It is acceptable for some plants and animals to go extinct to support human needs

f. It is my duty to act to protect people who may not have the power to protect themselves from environmental harm

g. I like to donate to protect natural areas even if I will never visit them in my lifetime

h. I contribute to environmental protection only if I see personal benefits commensurate with personal costs

i. It is important for me to protect the environment even if other people seem to be unconcerned

j. I'm not concerned about environmental

$\begin{array}{lll}0 & 0 & 0 \\ 0 & 0 & 0 \\ 0 & 0 & 0 \\ 0 & 0 & 0 \\ 0 & 0 & 0 \\ 0 & 0 & 0 \\ 0 & 0 & 0 \\ 0 & 0 & 0 \\ 0 & & \end{array}$

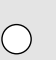


problems for which the effects won't be felt until after l'm long gone

k. Species of plants and animals have intrinsic value, even if they are not of any use to humans

I. We have a duty to ensure that future generations can live a life at least as fulfilling as the current generation

Nest, we have a few background questions to help us know whether we have reached a wide variety of people with our survey.

Q7. What month and year were you born?
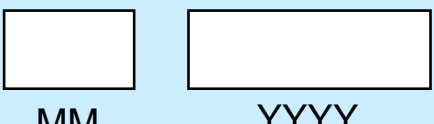

\section{Q8. What is your gender?}

Female

Male

Q9. What describes your highest level of education?

Primary School or less

High School (includes GED)

Some College or Associate's or Technical Degree

4-year College Degree (Bachelor's)

Graduate or Professional Degree (Master's, Ph.D., M.B.A., M.D., J.D., etc)

Q10. How conservative or liberal are you in your political views?

Extremely Conservative

Conservative

Slightly Conservative

Moderate

Slightly Liberal

Liberal

Extremely Liberal

Prefer Not to Answer 
Q11. Do you consider yourself...? (You can mark more than one.)

White

Black or African American

American Indian or Alaska native

Hispanic

Asian

Other (Please Specify)

Prefer Not to Answer

Q12. How many adults and children live in your household, including yourself?

Number of adults (18 years or older) living in my household

Number of children (17 years or younger) living in my household

Q13. Which of the following categories best describes the total annual income of your household from all sources in 2014, before taxes?

Less than $\$ 25,000$ per year

$\$ 25,001$ to $\$ 50,000$ per year

$\$ 50,001$ to $\$ 75,000$ per year

$\$ 75,001$ to $\$ 100,000$ per year

More than $\$ 100,000$ per year

Prefer Not to Answer

Q14. Please provide contact information below. We will contact with you in case you are selected to take part in this study.

First and Last Name:

Address:

Phone Number:

Email:

Preferred Contact Method

Phone

$\bigcirc$ Mail

$\bigcirc$ Email 
Thank you for taking time to respond to our survey! We appreciate your participation. Please use the space below to write any other comments or thoughts you may have. 


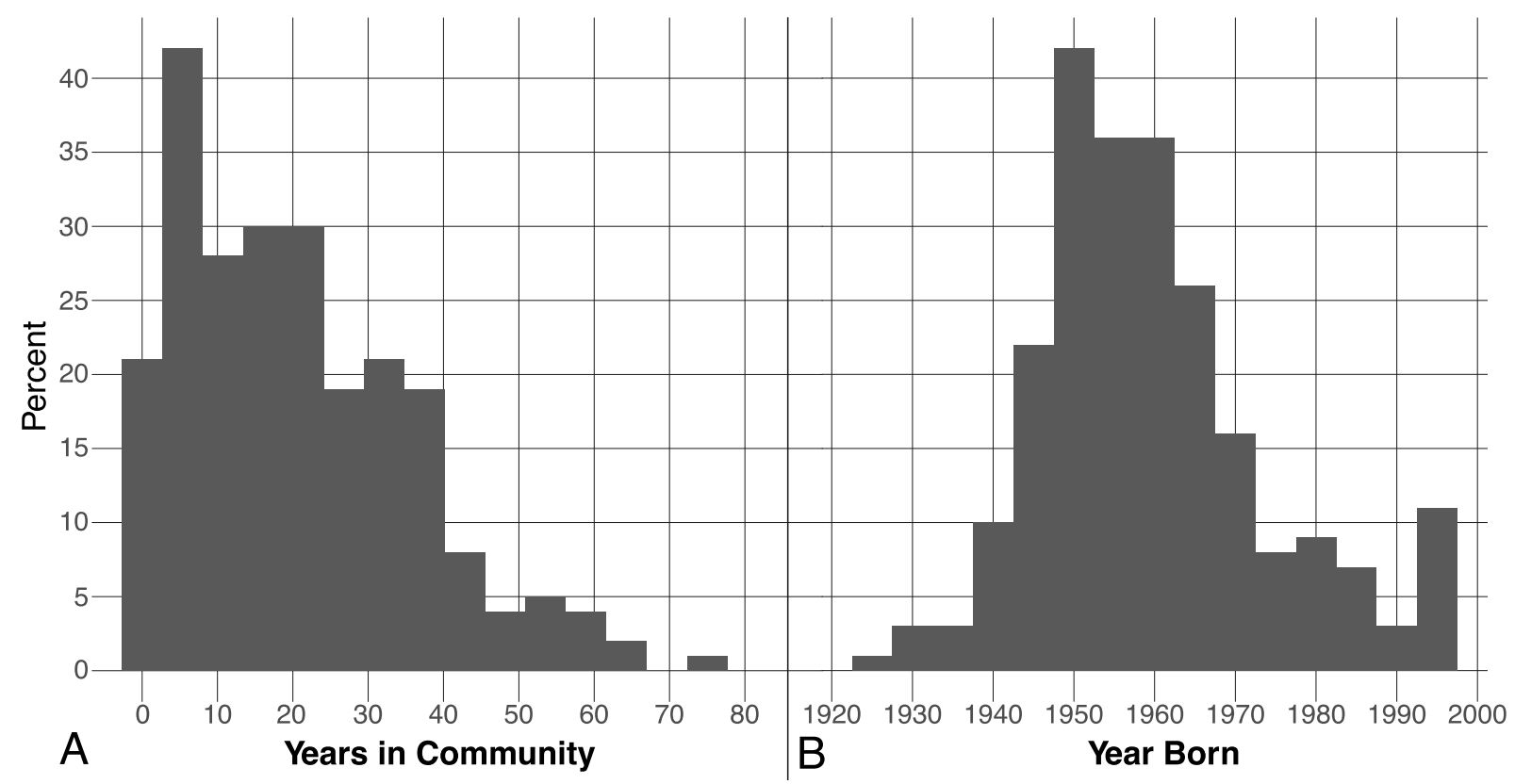

Figure S1. Demographic characteristics of the questionnaire survey respondents (A) years living in the community; (B) year born 


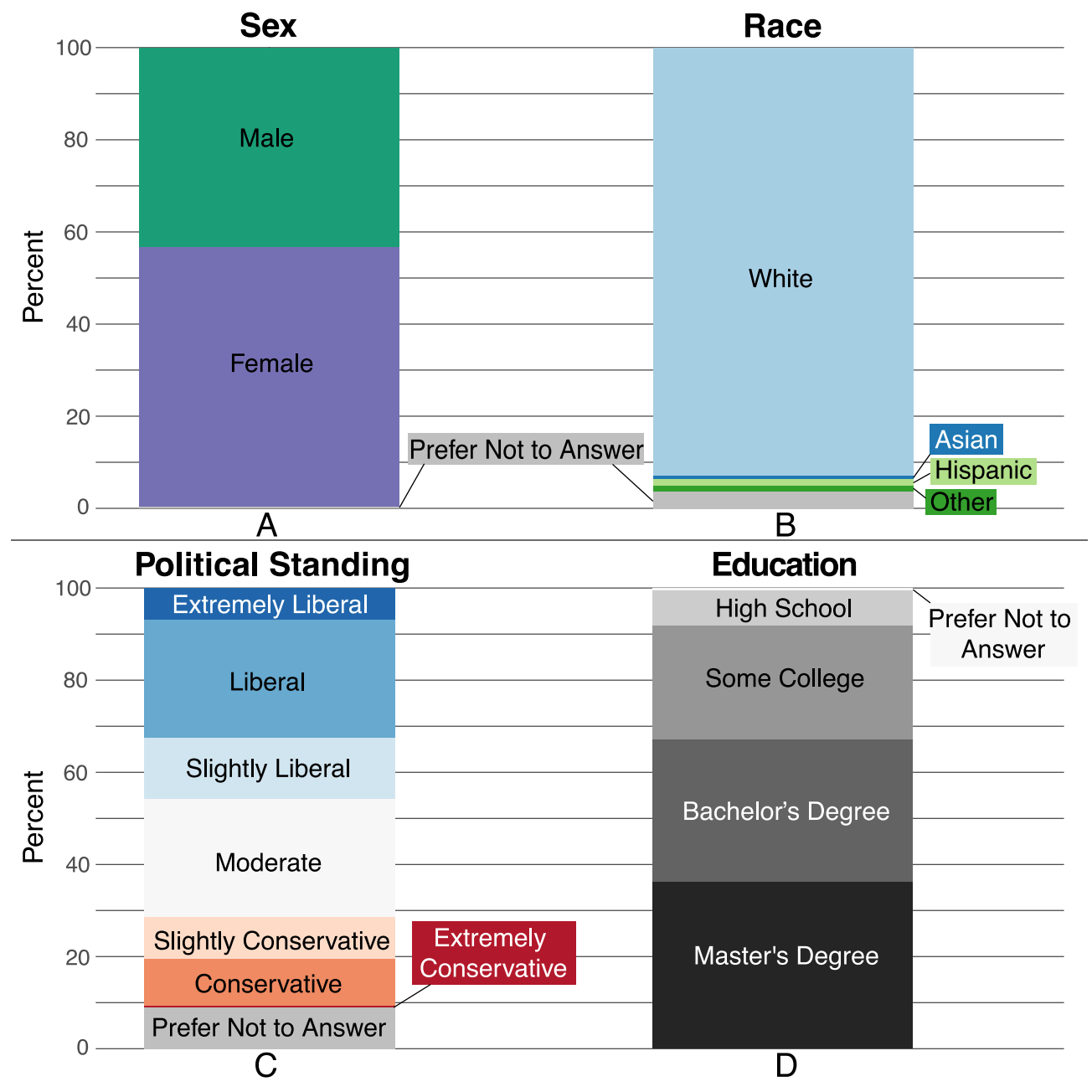

Figure S2. Demographic characteristics of the questionnaire survey respondents (A) gender; (B) race; (C) political standing and; (D) educational level. 
Table S1. Participants Characteristics compared to New Hampshire Population

\begin{tabular}{|c|c|c|}
\hline Characteristic & $\begin{array}{l}\text { NH } \\
\text { Population* }\end{array}$ & $\%$ of participants \\
\hline \multicolumn{3}{|l|}{ Gender } \\
\hline Female & $51 \%$ & $51 \%$ \\
\hline Male & $50 \%$ & $50 \%$ \\
\hline \multicolumn{3}{|l|}{ Age Group } \\
\hline 18 to 40 & $23.6 \%$ & $16 \%$ \\
\hline 41 to 50 & $16 \%$ & $13 \%$ \\
\hline 50 to 60 & $15.8 \%$ & $36 \%$ \\
\hline Over 60 & $19.7 \%$ & $34 \%$ \\
\hline \multicolumn{3}{|l|}{ Income } \\
\hline Less than $\$ 25,000$ per year & $15.8 \%$ & $10 \%$ \\
\hline$\$ 25,001$ to $\$ 50,000$ per year & $20.4 \%$ & $21 \%$ \\
\hline$\$ 50,001$ to $\$ 75,000$ per year & $18.3 \%$ & $17.91 \%$ \\
\hline$\$ 75,001$ to $\$ 100,000$ per year & $14.3 \%$ & $15 \%$ \\
\hline More than $\$ 100,000$ per year & $31.3 \%$ & $19 \%$ \\
\hline Prefer Not to Answer & NA & $16 \%$ \\
\hline \multicolumn{3}{|l|}{ Political Affiliation } \\
\hline $\begin{array}{l}\text { Extremely Conservative/ Conservative/Slightly } \\
\text { Conservative }\end{array}$ & $26 \%$ & $28 \%$ \\
\hline Extremely Liberal/ Liberal/Slightly Liberal & $30 \%$ & $28 \%$ \\
\hline Moderate/Unknown & $44 \%$ & $43 \%$ \\
\hline
\end{tabular}

*Data derived from U.S. Census Bureau (2016) and Secretary of State (2018) 
References

Mavrommati, G., M. E. Borsuk, and R. B. Howarth. 2017. A novel deliberative multicriteria evaluation approach to ecosystem service valuation. Ecology and Society 22.

Samal, N. R., W. M. Wollheim, S. Zuidema, R. J. Stewart, Z. Zhou, M. M. Mineau, M. E. Borsuk, K. H. Gardner, S. Glidden, T. Huang, D. A. Lutz, G. Mavrommati, A. M. Thorn, C. P. Wake, and M. Huber. 2017. A coupled terrestrial and aquatic biogeophysical model of the Upper Merrimack River watershed, New Hampshire, to inform ecosystem services evaluation and management under climate and land-cover change. Ecology and Society 22.

Secretary of State. 2018. Party Registration/Names on Checklist History.

U.S. Census Bureau. 2016. 2012-2016 American Community Survey 5-Year Estimates. 